\title{
Article \\ Xanthohumol Is a Potent Pan-Inhibitor of Coronaviruses Targeting Main Protease
}

\author{
Yuxi Lin ${ }^{1,2}{ }^{(D}$, Ruochen Zang ${ }^{3,4}$, Yanlong Ma ${ }^{5}$, Zhuoya Wang ${ }^{6}, \mathrm{Li} \mathrm{Li}^{2}{ }^{2}$, Siyuan Ding ${ }^{3}$, Rong Zhang ${ }^{5}$, \\ Zhiqiang Wei ${ }^{6}$, Jinbo Yang ${ }^{1,2,4,7, *}$ and Xin Wang ${ }^{2,4,7, *(1)}$
}

1 Institute of Cancer Biology and Drug Screening, School of Life Sciences, Lanzhou University, Lanzhou 730000, China; linyx18@lzu.edu.cn

2 Center for Innovation Marine Drug Screening and Evaluation, Pilot National Laboratory for Marine Science and Technology, Qingdao 266237, China; lili5890@ouc.edu.cn

3 Department of Molecular Microbiology, School of Medicine, Washington University, St. Louis, MO 63110, USA; ruochenzang@wustl.edu (R.Z.); siyuan.ding@wustl.edu (S.D.)

4 Key Laboratory of Marine Drugs of Ministry of Education, School of Medicine and Pharmacy, Ocean University of China, Qingdao 266003, China

5 Key Laboratory of Medical Molecular Virology (MOE/NHC/CAMS), Shanghai Institute of Infectious Disease and Biosecurity, School of Basic Medical Sciences, Shanghai Medical College, Fudan University, Shanghai 200032, China; 18111010054@fudan.edu.cn (Y.M.); rong_zhang@fudan.edu.cn (R.Z.)

6 Center for High Performance Computing and System Simulation, Pilot National Laboratory for Marine Science and Technology, Qingdao 266237, China; zywang3@qnlm.ac (Z.W.); zqwei@qnlm.ac (Z.W.)

7 Marine Biomedical Research Institute of Qingdao, Qingdao 266071, China

* Correspondence: yangjb@lzu.edu.cn (J.Y.); wx8399@ouc.edu.cn (X.W.); Tel.: +86-931-8915350 (J.Y.); +86-0532-85906820 (X.W.); Fax: +86-931-8915350 (J.Y.)

Citation: Lin, Y.; Zang, R.; Ma, Y.; Wang, Z.; Li, L.; Ding, S.; Zhang, R.; Wei, Z.; Yang, J.; Wang, X

Xanthohumol Is a Potent Pan-Inhibitor of Coronaviruses Targeting Main Protease. Int. J. Mol. Sci. 2021, 22, 12134. https://doi.org/ $10.3390 /$ ijms222212134

Academic Editor: Hye Gwang Jeong

Received: 28 September 2021

Accepted: 5 November 2021

Published: 9 November 2021

Publisher's Note: MDPI stays neutral with regard to jurisdictional claims in published maps and institutional affiliations.

Copyright: (c) 2021 by the authors. Licensee MDPI, Basel, Switzerland. This article is an open access article distributed under the terms and conditions of the Creative Commons Attribution (CC BY) license (https:// creativecommons.org/licenses/by/ $4.0 /)$.

\begin{abstract}
Coronaviruses cause diseases in humans and livestock. The SARS-CoV-2 is infecting millions of human beings, with high morbidity and mortality worldwide. The main protease (Mpro) of coronavirus plays a pivotal role in viral replication and transcription, which, in theory, is an attractive drug target for antiviral drug development. It has been extensively discussed whether Xanthohumol is able to help COVID-19 patients. Here, we report that Xanthohumol, a small molecule in clinical trials from hops (Humulus lupulus), was a potent pan-inhibitor for various coronaviruses by targeting $\mathrm{M}^{\text {pro }}$, for example, betacoronavirus SARS-CoV-2 ( $\mathrm{IC}_{50}$ value of $\left.1.53 \mu \mathrm{M}\right)$, and alphacoronavirus PEDV $\left(\mathrm{IC}_{50}\right.$ value of $\left.7.51 \mu \mathrm{M}\right)$. Xanthohumol inhibited $\mathrm{M}^{\text {pro }}$ activities in the enzymatical assays, while pretreatment with Xanthohumol restricted the SARS-CoV-2 and PEDV replication in Vero-E6 cells. Therefore, Xanthohumol is a potent pan-inhibitor of coronaviruses and an excellent lead compound for further drug development.
\end{abstract}

Keywords: Xanthohumol; natural product; SARS-CoV-2; PEDV; coronavirus

\section{Introduction}

Coronaviruses (CoVs) infect mammals and birds, leading to severe infectious diseases in rare cases. Most human coronavirus (hCoV) infections cause no, or mild, symptoms, but some become fatal, such as SARS-CoV-2, SARS-CoV, and MERS-CoV [1,2]. Animal coronaviruses lead to gross economic losses, with examples including the porcine epidemic diarrhea virus (PEDV), and the transmissible gastroenteritis virus (TGEV) [3]. To September 2021, SARS-CoV-2 has caused over 200 million infections and 4.58 million deaths worldwide. Vaccines have largely controlled viral infections, but various emerging variants are escaping the neutralization by vaccines. On the other hand, some coronaviruses infecting livestock have been reported to be zoonotic [4,5], which may be the origin for the next breakout. It is highly desirable to screen pan-inhibitors for emerging coronaviruses.

Coronaviruses are large positive-strand RNA viruses, with a unique life cycle, belonging to the Coronaviridae family [6]. After entry, viruses immediately translate two 
polyproteins, pp1a ( 450 kDa) and pp1ab $(\sim 750 \mathrm{kDa})$, using their genomic RNA, and generate 12-16 individual nonstructural proteins (NSPs) by the cleavages of the main protease ( $\mathrm{M}^{\text {pro }}$ or 3CLpro) and papain-like protease (PLpro). NSPs assemble into viral replication machinery, taking part in various critical processes, such as genome duplication, protein translation, and immune evasion [6]. To be noted, these viral proteins are highly conserved in the Coronaviridae family, which means chemicals targeting these proteins might inhibit multiple coronaviruses. Thus, people initially expected that the RdRp (RNA-dependent RNA polymerase) inhibitor, Remdesivir (GS-5734), could cure COVID-19 patients because its parent chemical, GS-441524, displayed antiviral activities against other CoVs $[7,8]$. Unfortunately, the unsuccessful clinical trials of Remdesivir for COVID-19 remind us that screening novel antiviral agents remains attractive, especially for pan-inhibitors against coronaviruses [9].

$\mathrm{M}^{\mathrm{pro}}$ is a viral-encoding cysteine protease [10]. Protease inhibitors are attractive candidates for antiviral drug development. Many protease inhibitors have been marketed as antiviral agents (i.e., Boceprevir for HCV, Darunavir for HIV). Because coronaviral $\mathrm{M}^{\text {pro }}$ is distinct from all human proteases [10], and critical in the viral life cycle, compounds that suppress $\mathrm{M}^{\text {pro }}$ activities may be pan-inhibitors of coronaviruses without side effects. The first generation of $\mathrm{M}^{\mathrm{pro}}$ is the covalent inhibitor, N3, which mimics the native substrate peptides with additional Michael acceptors as warheads [11]. More and more peptidic inhibitors/peptidomimetics have been developed with amazing activities and low toxicities, for example, GC-376, 11a, and 11b [12,13]. Moreover, $\mathrm{M}^{\mathrm{pro}}$ inhibitors have also been found via high-throughput screening approaches. Ebselen, PX-12, and carmofur may covalently interact with the $\mathrm{C} 145$ residue of $\mathrm{M}^{\text {pro }}$, which is critical to its catalytical activities [14]. Pfizer has announced the launch of a phase I clinical trial with PF-07321332 [15]. Until now, it is the first $\mathrm{M}^{\text {pro }}$ inhibitor in a clinical trial, and we are expecting the coming clinical results.

Plants are excellent resources for protease inhibitor discovery. Shikonin, a natural product from herbs, is a potential $\mathrm{M}^{\text {pro }}$ inhibitor against SARS-CoV-2 [14]. Phenolic compounds (PCs) from plants and their derivatives present antiviral activities against HSV-1, HIV, HCV, and others [16]. Phenolic compounds (PCs) are generally found in fruits, vegetables, herbs, flowers, and seeds, including phenolic acids and flavonoids (flavonols, catechins, flavones, chalcones, etc.). Xanthohumol is a prenylated chalcone from the hop plant (Humulus lupulus) that contributes to the bitterness in beer. It has been highly analyzed by researchers as an antiviral agent or antioxidant [17]. It has been reported to inhibit cervical cancer, colorectal cancer, and prostate cancer [18-21]. Our previous works found that Xanthohumol regulated the Th1/Th2 balance in a tumor model [22]. Xanthohumol inhibits HSV-1 with an $\mathrm{IC}_{50}$ value of $2.7 \mu \mathrm{g} / \mathrm{mL}$, HIV with an $\mathrm{IC}_{50}$ value of $\approx 20.74 \mu \mathrm{g} / \mathrm{mL}$, and $\mathrm{CMV}$ with an $\mathrm{IC}_{50}$ value of $2.5 \mu \mathrm{g} / \mathrm{mL}$ [23,24]. Because of its potent utilization of its antioxidant and anti-inflammatory properties, Xanthohumol has been approved in clinical studies for the safety and subjective tolerability in healthy adults (NCT03735420) [25]. After the breakout of COVID-19, many researchers keep discussing the potent roles of Xanthohumol against SARS-CoV-2. In this study, we found that Xanthohumol inhibited $\mathrm{M}^{\text {pro }}$, and that it was a potent pan-inhibitor against various coronaviruses. Xanthohumol restricted SARS-CoV-2 and PEDV in vitro. This suggests the potential of Xanthohumol as a coronavirus $\mathrm{M}^{\text {pro }}$ inhibitor.

\section{Results}

\subsection{Coronaviral $M^{\text {pro }}$ Is Highly Conserved}

$\mathrm{M}^{\text {pro }}$ contains three conserved domains: I, II, and III. Domain I and II are closely interacted to form a cleft, forming a catalytic core and substrate binding sites. His- 41 in Domain I, and Cys-145 in Domain II, are catalytic dyads [10,26]. As shown in Figure 1A, His41, Cys-145, and their neighbor residues were highly conserved in alpha-coronaviruses (i.e., PEDV and TGEV) and beta-coronaviruses (i.e., SARS-CoV and SARS-CoV-2). Moreover, the three-dimensional (3D) structures were similar for various $\mathrm{M}^{\text {pro }}$ (Figure 1B), and the amino acid sequences of Domain I and II were consistent in pathogenic coronaviruses (i.e., 
SARS-CoV-2, SARS-CoV, PEDV, and MERS-CoV) (Figure S1). This suggests that $\mathrm{M}^{\text {pro }}$ is a promising drug target for pan-inhibitor screening against coronaviruses. Interestingly, the cysteine protease inhibitor, GC376, is a potent $\mathrm{M}^{\text {pro }}$ inhibitor that shows antiviral activities against SARS-CoV-2, SARS-CoV, and feline coronavirus (FCoV) $[27,28]$. A recent study developed a pan-inhibitor of $\mathrm{M}^{\text {pro }}$ restricting multiple coronaviruses in vitro [29]. It suggests that $\mathrm{M}^{\text {pro }}$ inhibitors might be pan-inhibitors against coronaviruses.

A

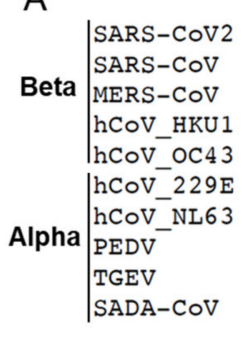

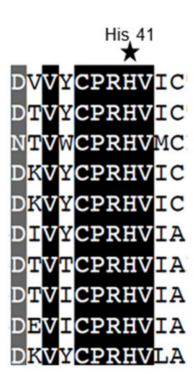

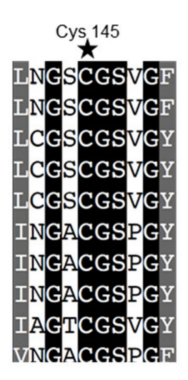

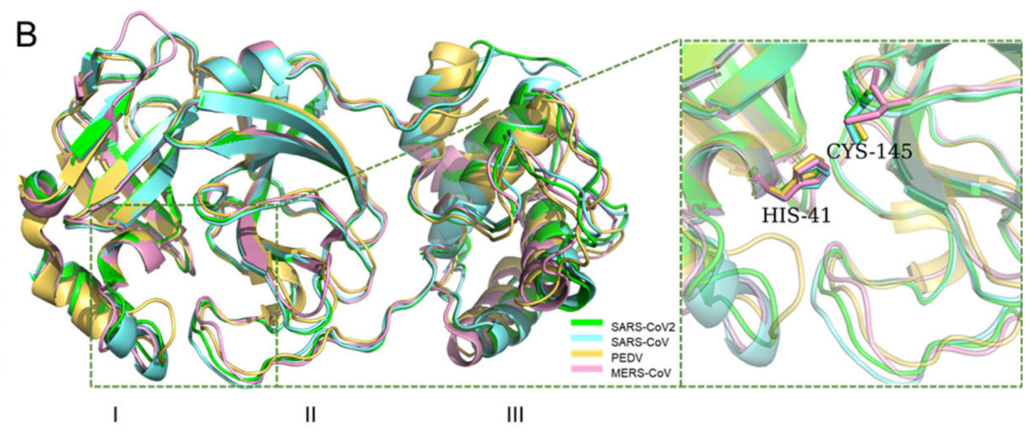

Figure 1. The conserved amino acid sequences and 3D structures of the Mpro catalytic domains for different coronaviruses. (A) Alignment of neighbor residues on both flanks of the pivotal residue His41, Cys145. (B) The three-dimensional (3D) structures of $\mathrm{M}^{\text {pro }}$ are highly conserved.

\subsection{SARS-CoV-2 $\mathrm{M}^{\text {pro }}$ Inhibitor Screening}

To screen $\mathrm{M}^{\text {pro }}$ inhibitors, recombinant GST-tagged $\mathrm{M}^{\text {pro }}$ was generated from the $\mathrm{E}$. coli BL21/DE3 strain (CodonPlus, Agilent Technologies Inc., Santa Clara, CA, USA;) using pGEX4 vectors. Since any additional amino acid residues in the $\mathrm{N}$-terminus of $\mathrm{M}^{\text {pro }}$ could reduce its activity [11,27], tags were removed by Factor Xa (P8010L, New England Biolab, Ipswich, MA, USA) to generate native $\mathrm{M}^{\text {pro }}$ proteins (Supplementary Figure S2A). The Michaelis constant $(\mathrm{Km})$ was measured to verify the hydrolase reaction. The Km value was $1.10 \pm 0.22 \mu \mathrm{M}$ (Supplementary Figure S2C), referring to a high affinity between the substrates and the enzyme.

The orchestrated protease system of cells is essential to many biological processes (i.e., misfolded protein degradation, inflammation, antimicrobe invasion, and digestion) that require the low toxicity of protease inhibitors as drug candidates. Since protease inhibitors are abundant in animals and plants, we decided to screen $\mathrm{M}^{\text {pro }}$ inhibitors from natural products, especially focusing on natural products from foods, food additives, and herbs, which were safe and easily accessible in theory. As shown in Supplementary Figure S2D, more than a hundred natural products were randomly picked from the compound bank and briefly screened at the final concentration of $50 \mu \mathrm{M}$. Hits were further tested in the presence of $10 \mu \mathrm{M}$ compounds, and candidates with an inhibition rate of more than $50 \%$ were considered as active. Surprisingly, Xanthohumol and MG132 almost abolished the enzyme activities of $\mathrm{M}^{\text {pro }}$ at the final concentration of $10 \mu \mathrm{M}$ (Figure 2A,B). MG132 is a well-established broad-spectrum proteasome inhibitor, used as a spy compound here.

It was found that Xanthohumol reduced $\mathrm{M}^{\text {pro }}$ hydrolase activities at low concentrations in vitro in a dose-dependent manner (Figure 2C,D). The half inhibition concentration of Xanthohumol on SARS-CoV-2 $\mathrm{M}^{\text {pro }}$ was $1.53 \pm 0.03 \mu \mathrm{M}$ (Figure 2D). As discussed in our early publications, the $\mathrm{IC}_{50}$ value of enzyme inhibitors is closely related to the enzymatical assay. To further analyze the inhibition efficiency of Xanthohumol on SARS-CoV-2 $\mathrm{M}^{\text {pro }}$, the $\mathrm{Ki}$ (the inhibition constant for the inhibitor) value was also measured, which was $0.57 \pm 0.01 \mu \mathrm{M}$ (Figure 2E). It indicated that Xanthohumol reduced SARS-CoV-2 Mpro enzymatic activities efficiently in vitro. 

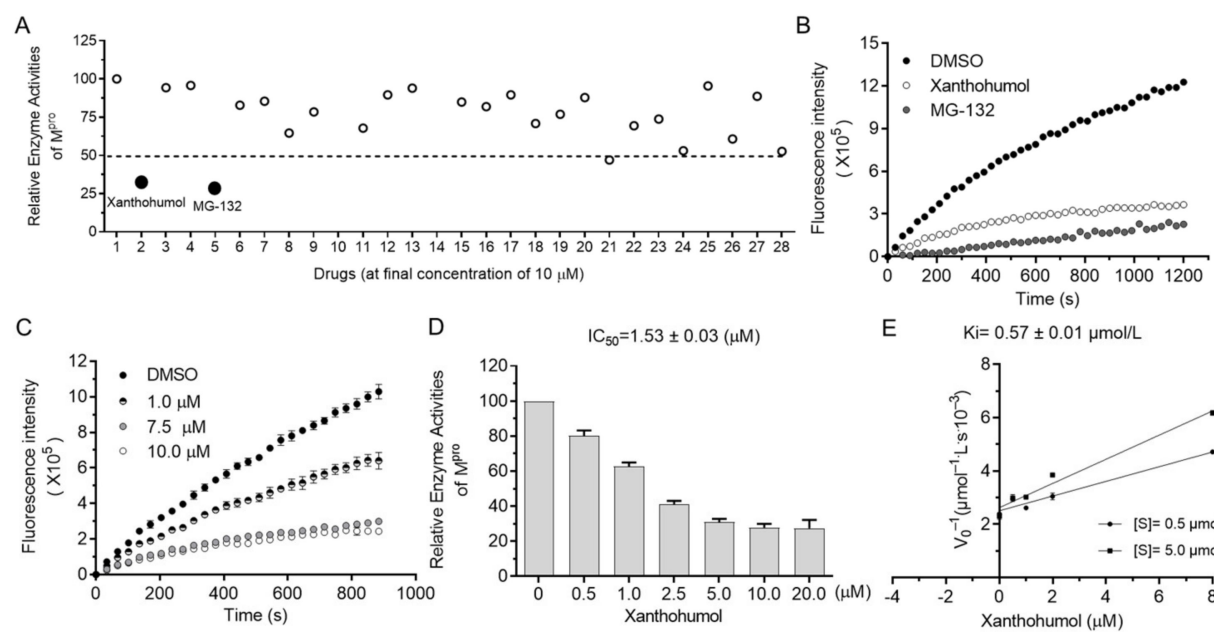

E

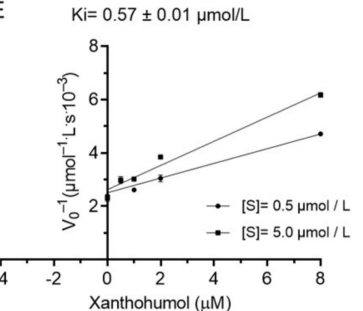

Figure 2. Xanthohumol inhibited hydrolase activities of SARS-CoV-2 Mpro in a dose-dependent manner. (A) Relative enzyme activities of SARS-CoV-2 Mpro in the presence of $10 \mu \mathrm{M}$ compounds. (B) The kinetic curves in the presence of Xanthohumol, MG132, and the solvent, DMSO. Xanthohumol and MG132 were added to the final concentration of $20 \mu \mathrm{M}$. (C) Xanthohumol inhibited Mpro dosedependently. (D) The $\mathrm{IC}_{50}$ value of Xanthohumol. (E) The Ki value of Xanthohumol on SARS-CoV-2 $M^{\text {pro }}$. Data are shown as means \pm standard error of mean (SEM) from three independent experiments.

\subsection{Xanthohumol Potentially Inhibits Various Coronaviral $M^{\text {pro }}$}

Coronaviruses are members of the Coronaviridae family. They are further subdivided into four genera: alpha-, beta-, gamma-, and delta- coronaviruses. The alpha- and betacoronaviruses infect only mammals [1]. Noting that the 3D structure and the catalytic dyads of $\mathrm{M}^{\text {pro }}$ are conserved in alpha- and beta- coronaviruses, we employed molecular docking to predict the potent inhibition activities of Xanthohumol against various coronaviruses. A high-quality crystal structure of SARS-CoV-2 $\mathrm{M}^{\text {pro }}$ has been reported earlier [10], and the crystal structures of SARS-CoV, MERS-CoV, PEDV, and TGEV M $^{\text {pro }}$ have been explored as well [30-33]. As shown in Figure 3A, Xanthohumol could be docked into the active pocket of a series of coronaviruses, $\mathrm{M}^{\text {pro }}$, and form hydrogen bonds and other molecular interactions. Most docking scores are between -6 to -8 , which indicate that Xanthohumol presents excellent affinities with various $\mathrm{M}^{\text {pro }}$ structures (Figure $3 \mathrm{~B}$ and Supplementary Data). To be noted, a hydrogen bond was found between Xanthohumol and the Cys145 of SARS-CoV-2 $\mathrm{M}^{\text {pro }}$ that was essential to $\mathrm{M}^{\text {pro }}$ catalytical activities, explaining that Xanthohumol inhibited SARS-CoV-2 efficiently. It indicated that Xanthohumol is a potent drug candidate for further drug development.

\subsection{Xanthohumol Restricts SARS-CoV-2 and PEDV Replication in the Cell-Based Assay}

Many chemicals presented significant inhibition efficiency in the enzymatic assay but failed in cell models because of their poor permeability, improper cellular metabolism, and other issues. We were wondering if Xanthohumol were able to hamper SARS-CoV-2 replication in cells. Calpeptin, a well-established cell-permeable cysteine protease inhibitor, was used as the positive control. Calpeptin significantly restricted SARS-CoV-2 infection $\left(\mathrm{IC}_{50}=0.38 \pm 0.01 \mu \mathrm{M}\right)$, indicating that the infection model could properly reveal the inhibition activity of candidate compounds (Supplementary Figure S3A). To be noted, Xanthohumol dose-dependently inhibited SARS-CoV-2 in cells (Figure 4A,B), while it did not slow cell growth, and only negligibly reduced cellular viability at the high concentration (Figure $4 \mathrm{C}$ ). In a plague assay, the $\mathrm{IC}_{50}$ value of Xanthohumol on SARS-CoV-2 was $5.93 \pm 0.45 \mu \mathrm{M}$ (Figure $4 \mathrm{~A}$ ). $\mathrm{M}^{\text {pro }}$ cleaves viral polyprotein to assemble viral replication machinery, which is critical for viral RNA duplication. This suggests that $\mathrm{M}^{\text {pro }}$ inhibitors could directly inhibit viral RNA replication by hampering the replication machinery assembly. To monitor whether Xanthohumol could inhibit SARS-CoV-2 RNA duplication by targeting its $\mathrm{M}^{\text {pro }}$, viral RNA loads of infected cells were also measured by qRT-PCR. 
This indicated that Xanthohumol could eliminate the viral genome effectively, which is highly consistent with the results from the plague assays mentioned above (Figure 4B). Moreover, the CC50 (the half cytotoxic concentration) value of Xanthohumol in Vero-E6 cells was $57.04 \pm 2.11 \mu \mathrm{M}$, and the selection index was more than 9.5. This suggests that Xanthohumol is an outstanding lead compound for further developments.

A
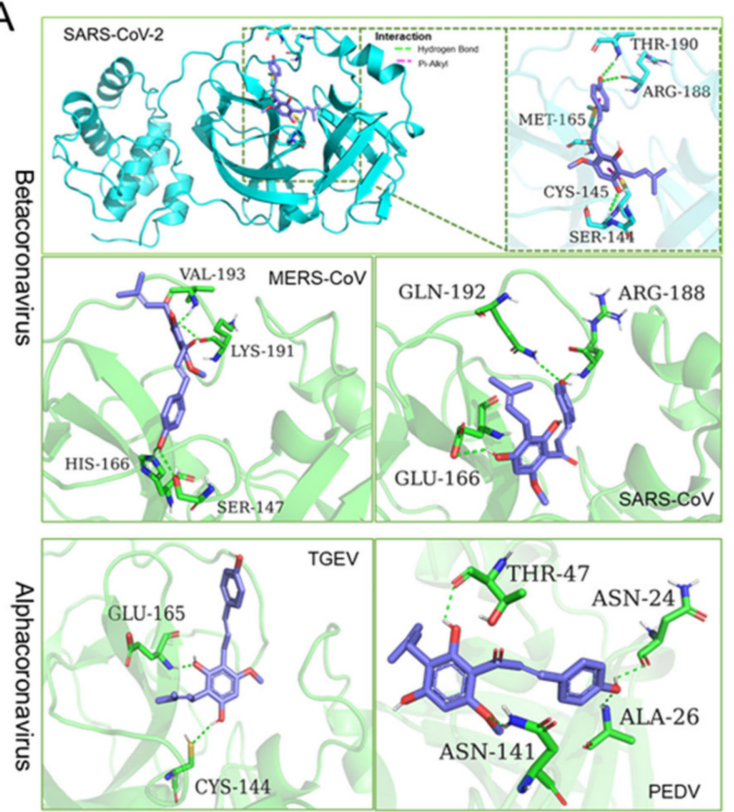

B

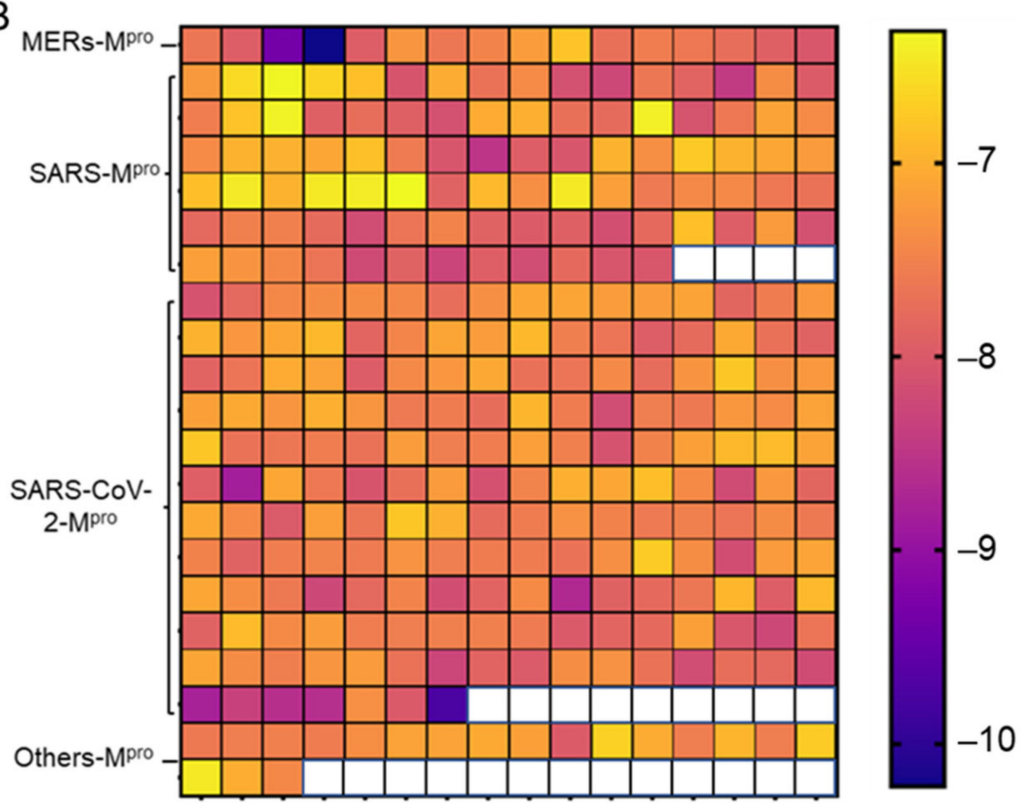

Figure 3. Xanthohumol is a potent pan-inhibitor of coronaviral $\mathrm{M}^{\mathrm{pro}}$. (A) The interaction pattern between Xanthohumol and indicated Mpro. The Mpro was shown in cyan and green. The Xanthohumol was presented in purple. (B) The affinity diagrams between Xanthohumol and different $M^{\text {pro }}$. $\mathrm{M}^{\text {pro }}$ structures were downloaded from PDB, and the PDB ID and detailed docking scores are shown in Supplementary Data.

A

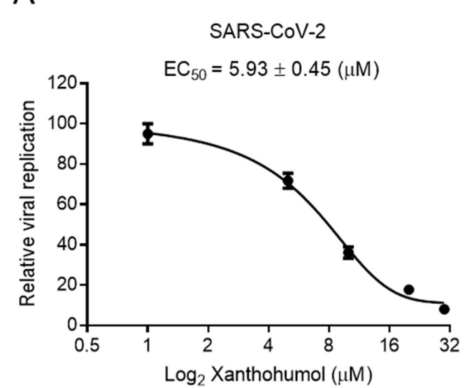

B

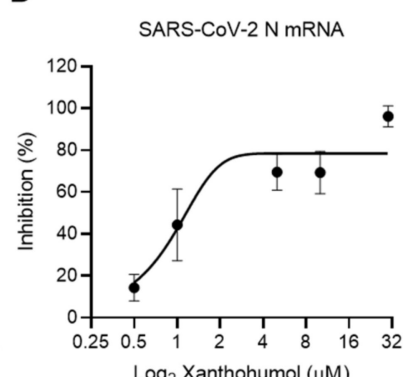

C

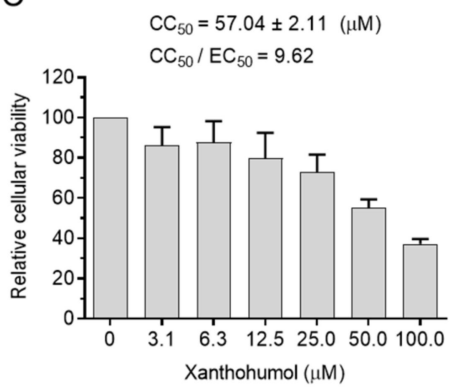

Figure 4. Xanthohumol inhibited SARS-CoV-2 replication in Vero-E6 cells. (A) Xanthohumol-inhibited SARS-CoV-2. Vero-E6 cells were pretreated with compounds at indicated concentrations for $1 \mathrm{~h}$, and then infected with recombinant SARS-CoV-2 mNeonGreen virus $(\mathrm{MOI}=0.5)$ for $24 \mathrm{~h}$. The green fluorescence was scanned as described. The $\mathrm{EC}_{50}$ values of Xanthohumol were calculated and are shown. (B) Xanthohumol reduced viral RNA loads. SARS-CoV-2 N mRNA was measured with qRT-PCR and normalized to GAPDH. (C) Cytotoxicities of Xanthohumol. Data are shown as means \pm SEM from three independent experiments.

Considering the structural similarity between PEDV and SARS-CoV-2 $\mathrm{M}^{\text {pro }}$, we were wondering if Xanthohumol would inhibit PEDV $\mathrm{M}^{\text {pro }}$ enzymatic activity and then restrict PEDV replication. The enzymatic assay was performed as SARS-CoV-2, in which the PEDV $\mathrm{M}^{\mathrm{pro}}$ was used instead of SARS-CoV-2 Mpro. It indicated that Xanthohumol inhibited PEDV $\mathrm{M}^{\text {pro }}$ efficiently with an $\mathrm{IC}_{50}$ value of $7.51 \pm 0.07 \mu \mathrm{M}$ (Figure 5A). Moreover, Xanthohumol dose-dependently inhibited PEDV in Vero-E6 cells (Figure 5B). 
A

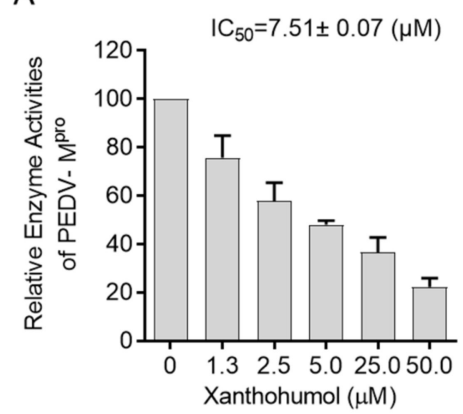

B

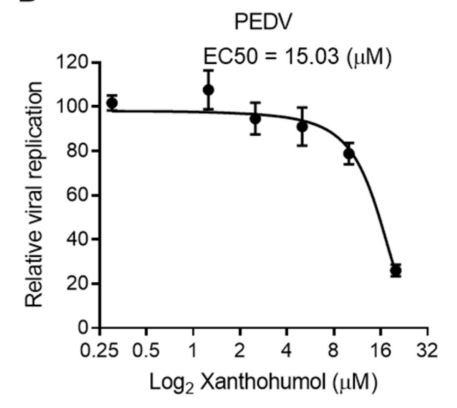

Figure 5. Xanthohumol inhibited PEDV $\mathrm{M}^{\text {pro }}$ and PEDV in vitro. (A) Xanthohumol inhibited PEDV $\mathrm{M}^{\mathrm{pro}}$. (B) Xanthohumol inhibited PEDV replication in vitro. Vero-E6 cells were pretreated with the indicated concentration of Xanthohumol for $1 \mathrm{~h}$ and infected with PEDV (MOI =1). Data are shown as means \pm SEM from three independent experiments.

\section{Discussion}

COVID-19 might recede soon. However, as the predicted Disease $\mathrm{X}$ by the WHO after the outbreak of SARS and MERS, coronaviral infections might routinely break out as the seasonal flu in the future. Moreover, coronaviruses are threatening livestock. It is still meaningful to screen safe, cheap, and broad-spectrum antiviral agents for coronaviruses. As shown in our study, Xanthohumol inhibited alpha- and beta- coronaviruses (Figures 4 and 5), which contain all fatal pathogenic coronaviruses: PEDV, SARS-CoV, MERS-CoV, and the recent SRAS-CoV-2 [34]. As previously reported, Xanthohumol modulated inflammation and oxidative stresses [35], which might benefit infected individuals, rather than an antiviral agent. At this moment, Xanthohumol is an excellent lead compound for drug optimization, and more detailed studies are required for further developments.

The safety and tolerability in healthy adults of Xanthohumol has been well-established, and Xanthohumol is available as dietary supplements and ingredients in medical foods. Although it is impossible to get enough Xanthohumol from beers before being severely hurt by alcohol, because of its relatively high $\mathrm{IC}_{50}$ value against coronaviruses, it is hoped that Xanthumol might guard healthy individuals against the initiation of infection at a low concentration. Of course, more detailed systematic studies should be performed before the usage of Xanthohumol for any medicinal purpose. In this case, using Xanthohumol in nonalcohol foods and drinks may be an available strategy. Hops are cheap and easily available in some areas. Coronaviruses are heavily damaging our livestock industry and using hops as feed additives may also be suggested.

Xanthohumol had been found to be a broad-spectrum antiviral agent, presenting inhibition activities against many viruses, which include human cytomegalovirus (CMV), herpes simplex virus (HSV), human immunodeficiency virus (HIV), hepatitis C virus $(\mathrm{HCV})$, and porcine reproductive and respiratory syndrome viruses (PRRSV) [36-38]. Recently, many researchers keep discussing the potent role of Xanthohumol or the crude extracts of hops in COVID-19 treatments [39,40]. However, it is still unknown whether Xanthohumol can inhibit coronaviruses, and the antiviral mechanism of Xanthohumol is elusive. It has been shown that its antioxidative activities could reduce viral-induced tissue damage, and Xanthohumol could also boost the antiviral activities of type I interferon [41,42]. In our study, we demonstrate that Xanthohumol target viral $\mathrm{M}^{\text {pro }}$ as a protease inhibitor. Interestingly, many protease inhibitors were clinically used for HIV treatments [43], of which Lopinavir, Indinavir, and Darunavir have been repurposed to inhibit SARS-CoV-2 Mpro [44]. The HCV NS3-4A protease drug, boceprevir, could inhibit SARS-CoV-2 replication by targeting $\mathrm{M}^{\text {pro }}$ in our and other groups' independent studies $[45,46]$. To be noted, PRRSV belongs to Arteriviridae. Both Arteriviridae and Coronaviridea are members of Nidovirales. PRRSV has a similar assembly process of replicase as coronaviruses. It encodes a polyprotein that is be cleaved by viral proteins (also called main protease and Papain-like protease as SARS-CoV-2). This suggests that 
Xanthohumol might inhibit HIV, HCV, PRRSV, and coronaviruses via a similar mechanism, being a protease inhibitor.

As mentioned above, because of the large number of infected individuals, the high mutation rates, and the potent zoonotic feature of coronaviruses [4], the war against coronaviruses will be a long one. It is necessary to screen potent pan-inhibitors for the next unexpected outbreak. Herein, identifying a promised drug target becomes critical. Xanthohumol showed a pan-inhibitor activity against alpha- and beta- coronaviruses targeting $\mathrm{M}^{\text {pro }}$, and the GC-376 could inhibit SARS-CoV, SARS-CoV-2, and the Feline coronavirus (FcoV) via inhibiting $\mathrm{M}^{\text {pro }}[10,27,28]$. A recently designed $\mathbf{M}^{\text {pro }}$ inhibitor also presented pan-inhibitor activities [10]. It will be interesting to screen $\mathrm{M}^{\text {pro }}$ inhibitors against coronaviral infection and to clarify whether $\mathrm{M}^{\text {pro }}$ is a promised drug target for the development of pan-inhibitors against various coronaviruses.

\section{Materials and Methods}

\subsection{Cell Culture and Reagents}

Vero-E6 cells (ATCC, VERO C1008 [Vero 76, clone E6, Vero E6] CRL-1586 ${ }^{\mathrm{TM}}$ ) were cultured in Dulbecco's modified Eagle's medium (DMEM) supplement, with $10 \%$ fetal bovine serum (FBS), penicillin $(100 \mathrm{IU} / \mathrm{mL})$, and streptomycin $(100 \mathrm{mg} / \mathrm{mL})$. Cells were maintained in the incubator at $37{ }^{\circ} \mathrm{C}$ with $5 \% \mathrm{CO}_{2}$. Candidate compounds were obtained from a chemical bank in the lab, which was originally purchased from TargetMol (Shanghai, China), or were synthesized by us. Xanthohumol, Calpeptin, Remdesivir, and MG132 were purchased from Selleck (Shanghai, China). We purchased 96-well black plates with transparent glass-bottoms from Cellvis (Shanghai, China).

\subsection{Drug Treatment and Viral Infection}

For cytotoxicity analysis, Vero-E6 cells (3000 cells/well) were seeded into 96-well plates. After $12 \mathrm{~h}$, the cells were treated with the indicated chemicals at the final concentration, as shown. At 48 -h post-treatment, $10 \mu \mathrm{L}$ of resazurin $(1 \mathrm{mg} / \mathrm{mL})$ was added to each well and incubated for $3 \mathrm{~h}$. The absorbance was measured on a SpectraMax i3 (Molecular Devices, San Jose, CA, USA).

For antiviral analysis, Vero-E6 cells were pretreated with Xanthohumol and Calpeptin for $1 \mathrm{~h}$ and infected with SARS-CoV-2 mNeonGreen virus (MOI = 0.5) [47]. At 24-h postinfection (hpi), the cells were fixed and scanned by Amersham Typhoon 5 (GE, Laurel, MD, USA). The fluorescence intensities were quantified by ImageJ (NIH). The mNeonGreen signals and the mRNA of the SARS-CoV-2 N gene were measured, as previously described [48]. For the PEDV analysis, cells were pretreated with Xanthohumol or Remdesivir for $1 \mathrm{~h}$ and then infected with PEDV $(\mathrm{MOI}=1)$ in the presence of drugs for $24 \mathrm{~h}$. Cells were harvested and fixed with $2 \%$ paraformaldehyde, permeabilized, and intracellularly stained with house-made mouse anti-PEDV nucleocapsid serum. Goat anti-mouse IgG, conjugated with Alexa Fluor 647 (Thermo Fisher, Waltham, MA, USA), was used as the secondary antibody. After two additional washes, cells were subjected to flow cytometry analysis (Thermo, Waltham, MA, USA) and data processing (FlowJo, Becton, Dickinson \& Company, Franklin Lakes, NJ, USA). Porcine epidemic diarrhea virus (PEDV) was propagated in Vero-E6 cells $[49,50]$.

\subsection{Protein Expression, Purification, and Enzymatic Assay}

Protein expression and enzymatical assays were performed as previously described, with minor modifications [51]. SARS-CoV-2 and PEDV M ${ }^{\text {pro }}$ were generated as described previously [51]. Protein purity was identified by Coomassie Brilliant Blue staining. The enzymatic activity of $\mathrm{M}^{\text {pro }}$ was measured by continuous kinetic assays using an identical fluorogenic substrate, MCA-AVLQ/SGFR-Lys (DNP)-Lys-NH2 (Apetide Co., Ltd., Shanghai, China), as previously described [51] (Supplementary Figure S2B). The fluorescence intensities were monitored by a microplate reader (SpectraMax i3x, Molecular Devices). The excitation and emission wavelengths were 320 and $405 \mathrm{~nm}$, respectively. Experiments 
were performed in $100 \mu \mathrm{L}$ buffer (50 mM Tris-HCl, 1 mM EDTA, pH 7.3) containing $100 \mathrm{nM}$ $\mathrm{M}^{\text {pro }}, 2 \mu \mathrm{M}$ substrate, and $1 \mu \mathrm{L}$ of the desired concentration of drugs. The compounds and the $\mathrm{M}^{\text {pro }}$ were incubated at RT for $15 \mathrm{~min}$. Reaction velocities were analyzed by SoftMax Pro. $\mathrm{EC}_{50}, \mathrm{Km}$, and Ki were calculated by GraphPad Prism6.

\subsection{Molecular Docking}

The Mpro structure information was obtained from the PDB databank (SARS-CoV-2: 6lu7; SARS-CoV: 3sn8; MERS-CoV: 4rsp; PEDV: 5gwz; TGEV: 1p9u). In addition, 378 of the $M^{\text {pro }}$ structure information, analyzed by different research groups, was also obtained from the PDB database. The details are available in SI1. The structures of the proteins were prepared via the Protein Preparation Wizard task from Schröndinger for structure optimization. The structures of the compounds were prepared by LigPrep of Schrödinger (Schrödinger), and docked into the $\mathrm{M}^{\text {pro }}$ substrate-binding domain by AutoDock Vina. The docking score was the top score of the different docked modes. The Mpro structural superposition was analyzed by PyMol alignment.

Supplementary Materials: The Supplementary Materials are available online at https:/ /www.mdpi. com/article/10.3390/ijms222212134/s1.

Author Contributions: X.W. and Y.L. designed and supervised the study, and wrote the manuscript; Y.L. performed the data analysis, with significant contributions from Y.L., R.Z. (Ruochen Zang), L.L., Y.M. and Z.W.(Zhuoya Wang); S.D., R.Z. (Rong Zhang) and Z.W. (Zhiqiang Wei) helped with methodology; J.Y. and X.W. contributed to with conceptualization, writing and funding acquisition. All authors have read and agreed to the published version of the manuscript.

Funding: This research was funded by the special scientific research fund for COVID-19 from the Pilot National Laboratory for Marine Science and Technology (Qingdao) (QNLM202001), the National Natural Science Foundation of China (81991525, 31700755), the Taishan Scholars Program (tsqn201909170), the Fundamental Research Funds for the Central Universities to X.W., the Innovative Leader of the Qingdao Program (19-3-2-26-zhc), and the National Natural Science Foundation of China (32041005).

Institutional Review Board Statement: Not applicable.

Informed Consent Statement: Not applicable.

Data Availability Statement: The data presented in this study are available upon request from the corresponding authors.

Acknowledgments: We acknowledge Xin Li for providing the expression vector, pGEX4T1-Mpro . Furthermore, the authors give thanks for the financial support from Washington University (St. Louis) and Shanghai Medical College.

Conflicts of Interest: The authors declare no conflict of interest.

\section{References}

1. Cui, J.; Li, F.; Shi, Z.L. Origin and evolution of pathogenic coronaviruses. Nat. Rev. Microbiol. 2019, 17, 181-192. [CrossRef]

2. Kirtipal, N.; Bharadwaj, S.; Kang, S.G. Evolution. From SARS to SARS-CoV-2, insights on structure, pathogenicity and immunity aspects of pandemic human coronaviruses. Infect. Genet. Evol. 2020, 85, 104502. [CrossRef] [PubMed]

3. Tizard, I.R. Vaccination against coronaviruses in domestic animals. Vaccine 2020, 38, 5123-5130. [CrossRef] [PubMed]

4. Edwards, C.E.; Yount, B.L.; Graham, R.L.; Leist, S.R.; Hou, Y.J.; Dinnon, K.H.; Sims, A.C.; Swanstrom, J.; Gully, K.; Scobey, T.D.; et al. Swine acute diarrhea syndrome coronavirus replication in primary human cells reveals potential susceptibility to infection. Proc. Natl. Acad. Sci. USA 2020, 117, 26915-26925. [CrossRef]

5. Lee, P.I.; Hsueh, P.R. Emerging threats from zoonotic coronaviruses-from SARS and MERS to 2019-nCoV. J. Microbiol. Immunol. Infect. 2020, 53, 365-367. [CrossRef]

6. Chen, Y.; Liu, Q.; Guo, D. Emerging coronaviruses: Genome structure, replication, and pathogenesis. J. Med. Virol. 2020, 92, 418-423. [CrossRef] [PubMed]

7. Wit, E.D.; Feldmann, F.; Cronin, J.; Jordan, R.; Feldmann, H. Prophylactic and therapeutic remdesivir (GS-5734) treatment in the rhesus macaque model of MERS-CoV infection. Proc. Natl. Acad. Sci. USA 2020, 117, 6771-6776. [CrossRef] [PubMed]

8. Amirian, E.S.; Levy, J.K. Current knowledge about the antivirals remdesivir (GS-5734) and GS-441524 as therapeutic options for coronaviruses. One Health 2020, 9, 100128. [CrossRef] [PubMed] 
9. Wang, Y.; Zhang, D.; Du, G.; Du, R.; Zhao, J.; Jin, Y.; Fu, S.; Gao, L.; Cheng, Z.; Lu, Q.; et al. Remdesivir in adults with severe COVID-19: A randomised, double-blind, placebo-controlled, multicentre trial. Lancet 2020, 395, 1569-1578. [CrossRef]

10. Jin, Z.; Du, X.; Xu, Y.; Deng, Y.; Liu, M.; Zhao, Y.; Zhang, B.; Li, X.; Zhang, L.; Peng, C.; et al. Structure of Mpro from SARS-CoV-2 and discovery of its inhibitors. Nature 2020, 582, 289-293. [CrossRef]

11. Xue, X.; Yang, H.; Shen, W.; Zhao, Q.; Li, J.; Yang, K.; Chen, C.; Jin, Y.; Bartlam, M.; Rao, Z. Production of authentic SARS-CoV $\mathrm{M}(\mathrm{pro})$ with enhanced activity: Application as a novel tag-cleavage endopeptidase for protein overproduction. J. Mol. Biol. 2007, 366, 965-975. [CrossRef] [PubMed]

12. Li, Q.; Kang, C.B. Progress in Developing Inhibitors of SARS-CoV-2 3C-Like Protease. Microorganisms 2020, 8 , 1250. [CrossRef] [PubMed]

13. Dai, W.; Zhang, B.; Jiang, X.M.; Su, H.; Liu, H. Structure-Based Design, Synthesis and Biological Evaluation of Peptidomimetic Aldehydes as a Novel Series of Antiviral Drug Candidates Targeting the SARS-CoV-2 Main Protease. BioRxiv 2020. [CrossRef]

14. Ma, C.; Hu, Y.; Townsend, J.A.; Lagarias, P.I.; Marty, M.T.; Kolocouris, A.; Wang, J. Ebselen, disulfiram, carmofur, PX-12, tideglusib, and shikonin are non-specific promiscuous SARS-CoV-2 main protease inhibitors. ACS Pharm. Transl. Sci. 2020, 3 , 1265-1277. [CrossRef]

15. Vandyck, K.; Deval, J. Considerations for the discovery and development of 3-chymotrypsin-like cysteine protease inhibitors targeting SARS-CoV-2 infection. Curr. Opin. Virol. 2021, 49, 36-40. [CrossRef]

16. Kowalczyk, M.; Golonko, A.; Świsłocka, R.; Kalinowska, M.; Parcheta, M.; Swiergiel, A.; Lewandowski, W.J. Drug Design Strategies for the Treatment of Viral Disease. Plant Phenolic Compounds and Their Derivatives. Front. Pharm. 2021, 12, 709104. [CrossRef] [PubMed]

17. Liu, X.; Song, Z.; Bai, J.; Nauwynck, H.; Zhao, Y.; Jiang, P. Xanthohumol inhibits PRRSV proliferation and alleviates oxidative stress induced by PRRSV via the Nrf2-HMOX1 axis. Vet. Res. 2019, 50, 61. [CrossRef]

18. Liu, W.; Li, W.; Liu, H.; Yu, X. Xanthohumol inhibits colorectal cancer cells via downregulation of Hexokinases II-mediated glycolysis. Int. J. Biol. Sci. 2019, 15, 2497-2508. [CrossRef] [PubMed]

19. Liu, H.; Zhang, L.; Li, G.; Gao, Z. Xanthohumol protects against Azoxymethane-induced colorectal cancer in Sprague-Dawley rats. Environ. Toxicol. 2020, 35, 136-144. [CrossRef] [PubMed]

20. Yong, W.K.; Malek, S.N.A. Xanthohumol induces growth inhibition and apoptosis in ca ski human cervical cancer cells. Evid. Based Complement. Altern. Med. 2015, 2015, 921306. [CrossRef] [PubMed]

21. Gieroba, B.; Arczewska, M.; Sławińska-Brych, A.; Rzeski, W.; Stepulak, A.; Gagoś, M. Prostate and breast cancer cells death induced by xanthohumol investigated with Fourier transform infrared spectroscopy. Spectrochim. Acta A Mol. Biomol. Spectrosc. 2020, 231, 118112. [CrossRef]

22. Zhang, W.; Pan, Y.; Gou, P.; Zhou, C.; Ma, L.; Liu, Q.; Du, Y.; Yang, J.; Wang, Q. Effect of xanthohumol on Th1/Th2 balance in a breast cancer mouse model. Oncol. Rep. 2018, 39, 280-288. [CrossRef]

23. Buckwold, V.E.; Wilson, R.J.; Nalca, A.; Beer, B.B.; Voss, T.G.; Turpin, J.A.; Buckheit, R.W., III; Wei, J.; Wenzel-Mathers, M.; Walton, E.M.; et al. Antiviral activity of hop constituents against a series of DNA and RNA viruses. Antivir. Res. 2004, 61, 57-62. [CrossRef]

24. Wang, Q.; Ding, Z.H.; Liu, J.K.; Zheng, Y.T. Xanthohumol, a novel anti-HIV-1 agent purified from Hops Humulus lupulus. Antivir. Res. 2004, 64, 189-194. [CrossRef]

25. Bradley, R.; Langley, B.O.; Ryan, J.J.; Phipps, J.; Hanes, D.A.; Stack, E.; Jansson, J.K.; Metz, T.O.; Stevens, J.F. Xanthohumol microbiome and signature in healthy adults (the XMaS trial): A phase I triple-masked, placebo-controlled clinical trial. Trials 2020, 21, 835. [CrossRef] [PubMed]

26. Yang, H.; Yang, M.; Ding, Y.; Liu, Y.; Lou, Z.; Zhou, Z.; Sun, L.; Mo, L.; Ye, S.; Pang, H.; et al. The crystal structures of severe acute respiratory syndrome virus main protease and its complex with an inhibitor. Proc. Natl. Acad. Sci. USA 2003, 100, 13190-13195. [CrossRef] [PubMed]

27. Fu, L.; Ye, F.; Feng, Y.; Yu, F.; Wang, Q.; Wu, Y.; Zhao, C.; Sun, H.; Huang, B.; Niu, P.; et al. Both Boceprevir and GC376 efficaciously inhibit SARS-CoV-2 by targeting its main protease. Nat. Commun. 2020, 11, 4417. [CrossRef] [PubMed]

28. Vuong, W.; Khan, M.B.; Fischer, C.; Arutyunova, E.; Lamer, T.; Shields, J.; Saffran, H.A.; McKay, R.T.; van Belkum, M.J.; Joyce, M.A.; et al. Feline coronavirus drug inhibits the main protease of SARS-CoV-2 and blocks virus replication. Nat. Commun. 2020, 11, 4282. [CrossRef]

29. Qiao, J.; Li, Y.S.; Zeng, R.; Liu, F.L.; Luo, R.-H.; Huang, C.; Wang, Y.-F.; Zhang, J.; Quan, B.; Shen, C.; et al. SARS-CoV-2 M pro inhibitors with antiviral activity in a transgenic mouse model. Science 2021, 371, 1374-1378. [CrossRef]

30. Zhu, L.; George, S.; Schmidt, M.F.; Al-Gharabli, S.I.; Rademann, J.; Hilgenfeld, R. Peptide aldehyde inhibitors challenge the substrate specificity of the SARS-coronavirus main protease. Antivir. Res. 2011, 92, 204-212. [CrossRef]

31. Tomar, S.; Johnston, M.L.; John, S.; Osswald, H.L.; Nyalapatla, P.R.; Paul, L.N.; Ghosh, A.K.; Denison, M.; Mesecar, A.D. Ligandinduced Dimerization of Middle East Respiratory Syndrome (MERS) Coronavirus nsp5 Protease (3CLpro): Implications for Nsp5 Regulation and the Development of Antivirals. J. Biol. Chem. 2015, 290, 19403-19422. [CrossRef] [PubMed]

32. Wang, F.; Chen, C.; Yang, K.; Xu, Y.; Liu, X.; Gao, F.; Liu, H.; Chen, X.; Zhao, Q.; Liu, X.J.; et al. Michael Acceptor-Based Peptidomimetic Inhibitor of Main Protease from Porcine Epidemic Diarrhea Virus. J. Med. Chem. 2017, 60, 3212-3216. [CrossRef]

33. Anand, K.; Ziebuhr, J.; Wadhwani, P.; Mesters, J.R.; Hilgenfeld, R. Coronavirus Main Proteinase (3CLpro) Structure: Basis for Design of Anti-SARS Drugs. Science 2003, 300, 1763-1767. [CrossRef] [PubMed] 
34. Zhu, N.; Zhang, D.; Wang, W.; Li, X.; Yang, B.; Song, J.; Zhao, X.; Huang, B.; Shi, W.; Lu, R.; et al. A Novel Coronavirus from Patients with Pneumonia in China, 2019. N. Engl. J. Med. 2020, 382, 727-733. [CrossRef]

35. Costa, R.; Negrão, R.; Valente, I.; Castela, A.; Duarte, D.; Guardão, L.; Magalhães, P.J.; Rodrigues, J.A.; Guimarães, J.T.; Gomes, P.J.; et al. Xanthohumol modulates inflammation, oxidative stress, and angiogenesis in type 1 diabetic rat skin wound healing. J. Nat. Prod. 2013, 76, 2047-2053. [CrossRef] [PubMed]

36. Gerhäuser, C. Broad spectrum antiinfective potential of xanthohumol from hop (Humulus lupulus L.) in comparison with activities of other hop constituents and xanthohumol metabolites. Mol. Nutr. Food Res. 2005, 49, 827-831. [CrossRef] [PubMed]

37. Liu, X.; Bai, J.; Jiang, C.; Song, Z.; Zhao, Y.; Nauwynck, H.; Jiang, P. Therapeutic effect of Xanthohumol against highly pathogenic porcine reproductive and respiratory syndrome viruses. Vet. Microbiol. 2019, 238, 108431. [CrossRef] [PubMed]

38. Yang, M.; Li, N.; Li, F.; Zhu, Q.; Liu, X.; Han, Q.; Wang, Y.; Chen, Y.; Zeng, X.; Lv, Y.; et al. Xanthohumol, a main prenylated chalcone from hops, reduces liver damage and modulates oxidative reaction and apoptosis in hepatitis $\mathrm{C}$ virus infected Tupaia belangeri. Int. Immunopharmacol. 2013, 16, 466-474. [CrossRef] [PubMed]

39. Caplin, M.; Chen, L. The Potential Role of Xanthohumol in SARS-CoV-2 Treatment-Globally Accessible and Economically Viable. Nutr. Diet. Suppl. 2020, 12, 201-204. [CrossRef]

40. Lucas, K.; Frhlich-Nowoisky, J.; Oppitz, N.; Ackermann, M. Cinnamon and Hop Extracts as Potential Immunomodulators for Severe COVID-19 Cases. Front. Plant. Sci. 2021, 12, 589783. [CrossRef]

41. Zhang, N.; Liu, Z.; Han, Q.; Chen, J.; Lv, Y. Xanthohumol enhances antiviral effect of interferon $\alpha$-2b against bovine viral diarrhea virus, a surrogate of hepatitis C virus. Phytomedicine 2010, 17, 310-316. [CrossRef] [PubMed]

42. Zhang, N.; Liu, Z.; Han, Q.; Chen, J.; Lou, S.; Qiu, J.; Zhang, G. Inhibition of bovine viral diarrhea virus in vitro by xanthohumol: Comparisons with ribavirin and interferon- $\alpha$ and implications for the development of anti-hepatitis $C$ virus agents. Eur. J. Pharm. Sci. 2009, 38, 332-340. [CrossRef]

43. Ghosh, A.K.; Osswald, H.L.; Prato, G.J. Recent Progress in the Development of HIV-1 Protease Inhibitors for the Treatment of HIV / AIDS. J. Med. Chem. 2016, 59, 5172-5208. [CrossRef]

44. Komatsu, T.S.; Okimoto, N.; Koyama, Y.M.; Hirano, Y.; Taiji, M. Drug binding dynamics of the dimeric SARS-CoV-2 main protease, determined by molecular dynamics simulation. Sci. Rep. 2020, 10, 16986. [CrossRef] [PubMed]

45. Manandhar, A.; Blass, B.E.; Colussi, D.J.; Almi, I.; Elokely, K.M. Targeting SARS-CoV-2 M3CLpro by HCV NS3/4a Inhibitors: In Silico Modeling and In Vitro Screening. J. Chem. Inf. Model. 2021, 61, 1020-1032. [CrossRef] [PubMed]

46. Hosseini, F.S.; Amanlou, M. Anti-HCV and anti-malaria agent, potential candidates to repurpose for coronavirus infection: Virtual screening, molecular docking, and molecular dynamics simulation study. Life Sci. 2020, 258, 118205. [CrossRef] [PubMed]

47. Xie, X.; Muruato, A.; Lokugamage, K.G.; Narayanan, K.; Zhang, X.; Zou, J.; Liu, J.; Schindewolf, C.; Bopp, N.E.; Aguilar, P.V.; et al. An Infectious cDNA Clone of SARS-CoV-2. Cell Host Microbe 2020, 27, 841-848.e3. [CrossRef]

48. Zang, R.; Case, J.B.; Yutuc, E.; Ma, X.; Shen, S.; Gomez Castro, M.F.; Liu, Z.; Zeng, Q.; Zhao, H.; Son, J.; et al. Cholesterol 25-hydroxylase suppresses SARS-CoV-2 replication by blocking membrane fusion. Proc. Natl. Acad. Sci. USA 2020, 117, 32105-32113. [CrossRef]

49. Hofmann, M.; Wyler, R. Propagation of the virus of porcine epidemic diarrhea in cell culture. J. Clin. Microbiol. 1988, 26, 2235-2239. [CrossRef] [PubMed]

50. Deng, X.; van Geelen, A.; Buckley, A.C.; O’Brien, A.; Pillatzki, A.; Lager, K.M.; Faaberg, K.S.; Baker, S.C. Coronavirus Endoribonuclease Activity in Porcine Epidemic Diarrhea Virus Suppresses Type I and Type III Interferon Responses. J. Virol. 2019, 93, 2000-2018. [CrossRef] [PubMed]

51. Li, Z.; Li, X.; Huang, Y.Y.; Wu, Y.; Liu, R.; Zhou, L.; Lin, Y.; Wu, D.; Zhang, L.; Liu, H.; et al. Identify potent SARS-CoV-2 main protease inhibitors via accelerated free energy perturbation-based virtual screening of existing drugs. Proc. Natl. Acad. Sci. USA 2020, 117, 27381-27387. [CrossRef] [PubMed] 